\title{
PIPES DE BRECHA E ATIVIDADE MAGMÁTICA EXPLOSIVA NO COMPLEXO ALCALINO-CARBONATÍTICO DE CATALÃO I, GOIÁS
}

\author{
CARLOS CORDEIRO RIBEIRO ${ }^{1,2}$, JOSÉ AFFONSO BROD ${ }^{2}$, IVAN ALEJANDRO PETRINOVIC ${ }^{3}$, JOSÉ CARLOS \\ GASPAR $^{2,4} \&$ TEREZA CRISTINA JUNQUEIRA BROD ${ }^{2,4}$
}

\begin{abstract}
RESUMO Estruturas formadas por atividade magmática explosiva e fluxo turbulento ocorrem na área denominada Lagoa Seca, Complexo de Catalão 1, Goiás. O complexo é composto por rochas silicáticas (dunitos, clinopiroxenitos) e carbonatitos (sövitos, beforsitos, com foscoritos, nelsonitos e monazititos associados). Intenso metassomatismo carbonatítico provocou a conversão generalizada de rochas ultramáficas em flogopititos. A região da Lagoa Seca é uma depressão preenchida por sedimentos lacustres, que repousam em discordância sobre uma seqüência magmática acamadada. com espessura em torno de $15 \mathrm{~m}$, composta por apatitito, na base, e camadas de monazita, ilmenita e material argilizado no topo. Pipes de seção circular a elíptica ocorrem no interior da sequêencia magmática, em uma zona limitada por foscoritos e carbonatitos, na base, e pela própria discordância, no topo. A maioria dos pipes é preenchida por brecha, contendo fragmentos das encaixantes imediatas. A porção inferior de alguns pipes é dominada por material fino com estruturas típicas de fluxos particulados diluídos, em regime de fluxo turbulento (surges). Estas evidências indicam atividade explosiva e fragmentação do magma ainda no interior da câmara.
\end{abstract}

Palavras-chave: magmatismo explosivo, carbonatito, Catalão I, APIP, pipes intracâmara

\begin{abstract}
BRECCIA PIPES AND EXPLOSIVE MAGMATIC ACTIVITY IN THE CATALÃO I ALKALINE-CARBONATITE COMPLEX, GOIÁS Products of explosive magmatic activity and turbulent flow structures occur in the Lagoa Seca area of the Catalão I carbonatite complex, Goiás State, Brazil. The complex consists of silicate rocks (dunite, clinopyroxenite) and carbonatites (sövite, beforsite and associated phoscorite, nelsonite, and monazitite). Extensive carbonatite metasomatism converted the ultramafic rocks into widespread phlogopitites. In the Lagoa Seca area, lacustrine sediments discordantly overlie a 1.5 -metre thick unit of horizontally-layered alkaline rocks, composed of a basal apatitite overlain by layers of monazite, ilmenite and clay. This magmatic unit contains cylinder-shaped pipes with circular to elliptical cross-section, limited at the top by the discordance and at the bottom by phoscorites and carbonatites. The pipes are typically filled with coarse-grained breccia, containing fragments of country rocks from the immediate vicinity. The lower portion of some pipes is dominated by fine-grained material, with structures typical of diluted flows (surges), such as cross-bedding and coarsening-upward bedding. This suggests explosive activity and magma fragmentation within the magma chamber:
\end{abstract}

Key'words: explosive magmatism, carbonatite, Catalão I, APIP, chamber pipes

INTRODUÇÃO O intenso magmatismo ultrapotássico que afetou o sudeste de Goiás e oeste de Minas Gerais, durante o Cretáceo Superior, produziu um conjunto de kamafugitos, kimberlitos, lamproitos e complexos carbonatíticos, agrupados por Gibson et al. (1995) sob a designação de Província Ígnea do Alto Paranaíba. Os magmas alcalinos alojaram-se nos metamorfitos neoproterozóicos da Faixa Brasília, em uma faixa estreita entre os limites nordeste da Bacia do Paraná e sudoeste do Craton do São Francisco, formando diques, pipes, plugs, diatremas, derrames de lava, depósitos piroclásticos e complexos plutônicos.

Diversos autores (Herz 1977, Toyoda et al. 1994, Gibson et al. 1995a, 1995b, 1997, VanDecar et al 1995, Thompson et al 1998, Brod et al. 2000) associam a Província à influência termal e/ou química de uma pluma mantélica que impactou a base da litosfera continental Silva et al. (1979), Gomes et al. (1990) e Brod et al. (2000) salientam a associação espacial c temporal dos grandes complexos carbonatíticos com as lavas $\mathrm{e}$ intrusões sub-vulcânicas da Província.

Os complexos carbonatíticos do Alto Paranaíba compreendem Catalão I e Catalão II, no Estado de Goiás, e Serra Negra, Salitre I, Salitre II, Araxá e Tapira, no Estado de Minas Gerais. Compõem-se de um conjunto de rochas silicáticas, dominante- mente ultramáficas, com sienitos subordinados, e de um conjunto de carbonatitos, principalmente sövitos e beforsitos.

Diques lamprofíricos intimamente associados aos complexos foram denominados por Gibson et al (1995) de flogopita picritos. Brod (1999) e Brod et al. (2000) estabeleceram as relações de filiação entre flogopita picritos e complexos carbonatíticos, demonstrando que os primeiros representam o magma parental silicático, de afinidade kamafugítica e rico em $\mathrm{CO}_{2}$, do qual derivaram, por cristalização fracionada e imiscibilidade de líquidos, os demais litotipos ígneos dos complexos. A presença de xenólitos de bebedouritos e sienitos ultrapotássicos em kamafugitos da Formação Mata da Corda reforça a associação kamafugito-carbonatito na Província c sugere que câmaras magmáticas semelhantes aos complexos carbonatíticos sejam os equivalentes plutônicos dos kamafugitos (Seer \& Morais 1988, Seer et al. 1989, Brod et al 2000).

COMPLEXO DE CATALÃO I O complexo situa-se sobre a divisa dos municípios de Catalão/Ouvidor, no sudeste do Estado de Goiás, $20 \mathrm{~km}$ a nordeste da cidade de Catalão e distante $300 \mathrm{~km}$ de Brasília pela rodovia BR-050. Suas coordenadas geográficas são $18^{\circ} 08^{\prime} \mathrm{S}$ e $47^{\circ} 48^{\prime} \mathrm{W}$. Sua área aflorante é de

IUltrafértil S.A., Catalão, GO.e-mail: carloscordeiro@fosfertil-ultrafertil.com.br; cordrib@unb.br

2 Instituto de Geociências, Universidade de Brasília. Campus Asa Norte, 70.910-900 - Brasília - DF, e-mail: gasp@unb.br, brod@unb.br, tcjbrod@ unb.br

3 CONICET/Universidad de Salta, Argentina.e-mail: petrino@unsa.edu.ar

4 Bolsista do CNPq - Brasil 
$27 \mathrm{~km}^{2}$, constituindo um platô sub-circular, com eixos N-S e EW medindo respectivamente 6,0 e $5,5 \mathrm{~km}$. A intrusão é circundada por metamorfitos do Grupo Araxá arqueados em forma dômica (Carvalho 1974). Espesso manto de intemperismo cobre as rochas alcalinas, restringindo a obtenção de amostras frescas principalmente a testemunhos de sondagem.

Carvalho (1974) propôs o nome silicocarbonatito para designar o conjunto de glimeritos (flogopititos), piroxenitos, peridotitos, veios e plugs carbonatíticos, modificados ou não por metassomatismo ou serpentinização. Descreveu ainda glimeritos restritos, localizados às bordas do domo, e silexitos que ocorrem de maneira irregular em várias partes da intrusão, com espessuras de até $100 \mathrm{~m}$. Além da intensa venulação por carbonatito, Carvalho (1974) sugere a presença de plugs carbonatíticos na parte central do domo, cujo teto está totalmente silicificado. Descreve ainda sedimentos argilosos com até 150 m de espessura, em uma profunda depressão na parte central do domo, conhecida por Lagoa Seca, interpretando esta estrutura como uma dolina de dissolução formada sobre um stock carbonatítico.

Vários autores propuseram uma evolução multifásica para o complexo. Baecker (1983) sugeriu uma evolução magmática para o depósito de nióbio de Catalão I, envolvendo um conjunto de rochas ultramáficas alcalinas e um conjunto de carbonatitos, espacial e temporalmente associados. Para Gierth et al. (1985) a evolução se deu em quatro estágios: a) ultramáfico, caracterizado pela associação olivina-titanomagnetita; b) carbonatítico, caracterizado por flogopita, apatita, óxidos e carbonatos e flogopitização da serpentina; c) hidrotermal, caracterizado pelas mineralizações de sulfetos, clorita, barita, quartzo e remobilizações de carbonato; d) decomposição intempérica, culminando na remobilização, lixiviação e concentração de elementos e minerais em diversas posições do perfil de alteração. Danni et al. (1991) sugerem que os magnetita-dunitos e clinopiroxenitos de Catalão I são adcumulados formados pelo fracionamento de olivina, titanomagnetita e egerina-augita, a partir de um líquido com composição inicial de olivina nefelinito. Segundo Pereira (1995), foscoritos e piroxenitos estão associados ao inicio da atividade magmática, sucedendo-se uma fase de metassomatismo, responsável pela transformação da olivina em flogopita e pela mineralização da rocha em nióbio e, finalmente, eventos carbonatíticos e hidrotermais tardios. Araújo (1996) definiu uma seqüência composta por dunitos, piroxenitos, foscoritos, flogopititos, carbonatitos e uma brecha carbonatítica. A autora reconhece duas fases magmáticas principais: a) ultramáfica, representada por dunitos e clinopiroxenitos e b) carbonatítica, caracterizada por múltiplos estágios de atividade.

Toledo (1999), Neumann (1999) e Tassinari (2001) estudaram, sob o ponto de vista mineralógico e tecnológico, os depósitos de apatita e monazita identificados e quantificados por Carvalho (1974). Segundo Neumann (1999) e Toledo (1999) os depósitos de terras raras em monazita do Córrego do Garimpo podem ser de três tipos: a) em carbonatos dolomíticos; b) em saprolito e c) em silexito. Tassinari (2001) estudou os depósitos de monazita do Córrego do Garimpo e da Lagoa Seca com ênfase no processo de flotação destes minérios, além de caracterizar mineralogicamente a monazita.

Ribeiro \& Gaspar (2000) propõem uma cartografia dos tipos petrográficos com base em características geoquímicas, na área de decreto da empresa Ultrafértil SA, que ali possui uma mina com exploração de apatita (Fig. 1).

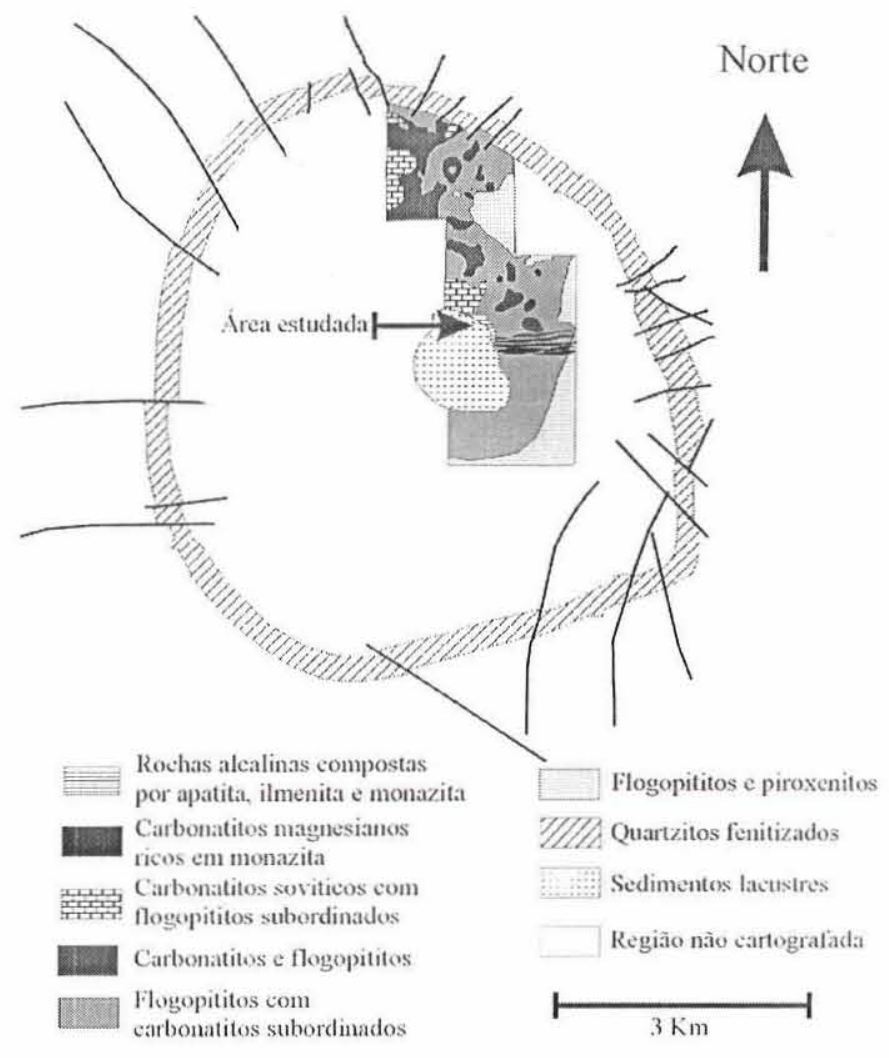

Figura l - Esboço geológico da parte centro-nordeste do domo carbonatítico de Catalão I (Ribeiro \& Gaspar 2000)

GEOLOGIA NA LOCALIDADE DA LAGOA SECA A região denominada Lagoa Seca localiza-se na parte central do complexo Catalão I, onde sedimentos lacustres de idade não determinada foram detectados tanto por sondagens como pelas escavações a céu aberto da mina de apatita da Ultrafértil. A área fonte dos sedimentos abrange tanto o próprio complexo quanto as encaixantes imediatas.

O contato entre os sedimentos lacustres e as rochas magmáticas é marcado por uma discordância erosiva sob a qual, na porção norte e mais rasa da bacia, ocorrem dois conjuntos de rochas alcalinas e pipes associados, que são o objeto principal deste trabalho (Fig. 2).

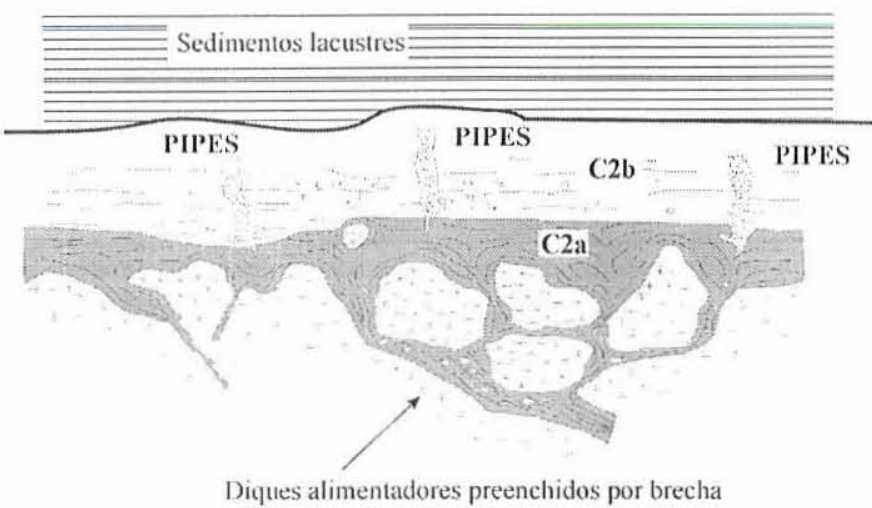

Figura 2 - Relações entre os conjuntos Cl, C2a e C2b, e os sedimentos lacustres da lagoa seca. 

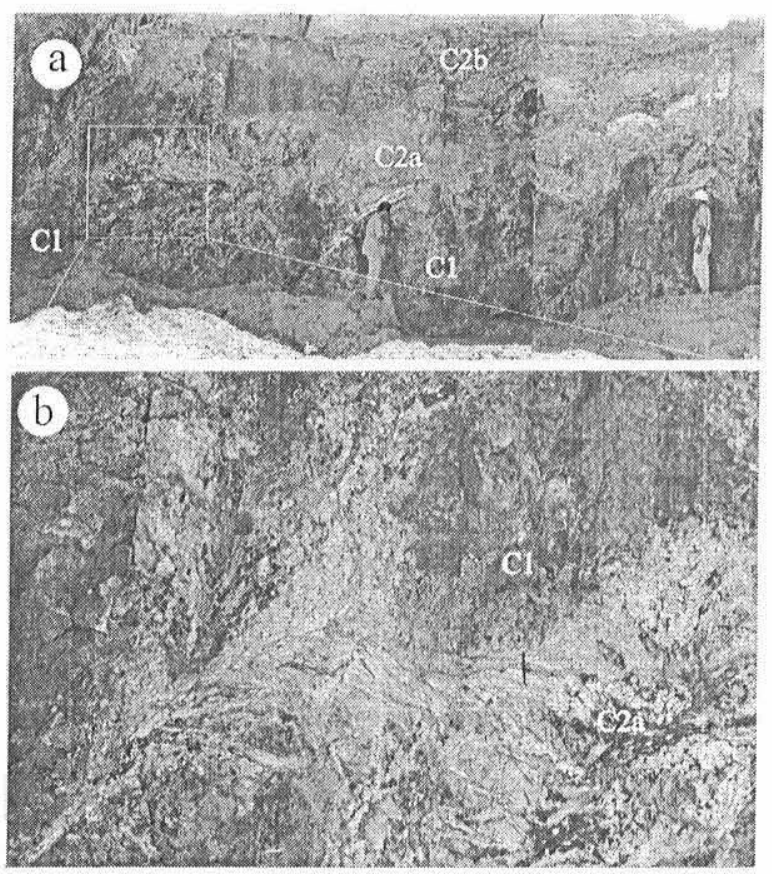

Figura 3- (a) Cl - carbonatitos e rochas da série foscorítica. C2a-rocha rica em apatita, monazita, e agregados lamelares de ilmenita. C2b - rocha bandada muito rica em monazita, com bandas de ilmenita e fosfato secundário subordinadas; (b) Detalhe de intrusão de diques com contatos irregulares de C2 em $\mathrm{Cl}$.

O primeiro conjunto, denominado $\mathrm{Cl}$, está intensamente intemperizado, mas a abundância de apatita e correlações com porções menos alteradas do complexo sugerem que as rochas originais eram carbonatitos e membros da série foscorítica, especialmente apatititos e nelsonitos. A cor de alteração varia entre ocre e marrom escuro.

Diques compostos de apatita $(>60 \%)$, agregados lamelares de ilmenita $(20 \%)$, monazita $(10 \%)$ e uma massa escura fina, dominada por argilominerais, são interpretados como os condutos alimentadores que deram origem às rochas da unidade $\mathrm{C} 2$. Estes diques, ao mesmo tempo em que cortam $\mathrm{Cl}$, dissolvem e incorporam fragmentos desta unidade (Fig. 2), desenvolvendo, junto ao contato, zonas enriquecidas em apatita no interior do dique (Fig. 3). Próximo ao topo de Cl, os diques tendem a alargar-se e adquirem forma de cúspide invertida, passando a recobrir o conjunto Cl (Fig. 2). Esta feição é acompanhada por uma mudança na orientação da estrutura de fluxo dos diques, que passa de vertical, no interior de $\mathrm{Cl}$, até horizontal, no interior de $\mathrm{C} 2$.

O conjunto $\mathrm{C} 2$ tem espessura de até $15 \mathrm{~m}$ e é dividido em unidade inferior (C2a) e superior (C2b).

A unidade $\mathrm{C} 2 \mathrm{a}$ varia de poucos centímetros a $5 \mathrm{~m}$ de espessura e amolda-se sobre a topografia irregular de $\mathrm{C} 1$, corroída e erodida pela entrada dos diques alimentadores (Fig. 3). É composta por apatita e agregados de lamelas orientadas de ilmenita, cujas dimensões e organização interna (Fig. 4) sugerem tratar-se de ilmenita exsolvida de antigos cristais de titanomagnetita, onde a magnetita foi lixiviada. Feições semelhantes foram descritas em Catalão I por Gaspar et cl. (1994).

A unidade $\mathrm{C} 2 \mathrm{~b}$ tem espessura entre 1 e $10 \mathrm{~m}$. Bandamento composicional é marcado por camadas horizontais milimétricas a métricas onde dominam ora agregados globulares verde-claro de monazita, ora agregados lamelares de ilmenita, ora fosfato secundário. Tassinari (2001) caracterizou os agregados de monazita como microcristalinos, com cristálitos na ordem de poucos microns, raramente atingindo $0,037 \mathrm{~mm}$ (Fig. 5). Os agregados lamelares de ilmenita e os fosfatos secundários, ocorrem como camadas ou lentes centimétricas, isoladas ou conectadas por níveis horizontais finos. Tassinari (2001) identificou ainda gorceixita e, subordinadamente, anatásio, quartzo, argilominerais, niobatos (bário pirocloro), zircão, barita e óxidos de ferro.

Corpos discordantes compreendem veios injetados em $\mathrm{Cl} \mathrm{e}$ $\mathrm{C} 2$ e diques e pipes, alojados dominantemente em C2. Estes corpos serão descritos em detalhe abaixo.

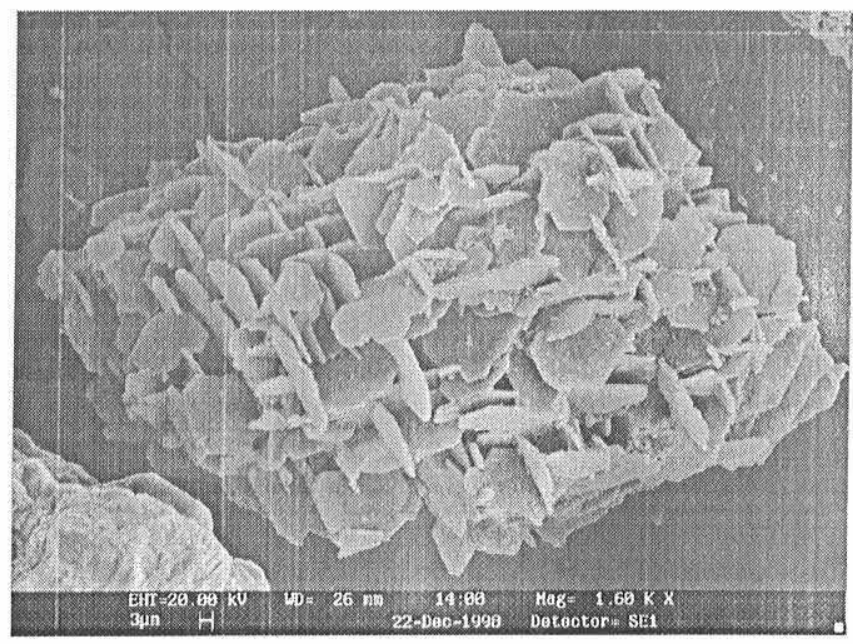

Figura 4 - Relictos de lamelas de exsolução de ilmenita em antigo grão de magnetita. MEV, elétrons secundários. Note a pequena espessura das lamelas, da ordem de $2 \mathrm{~mm}$

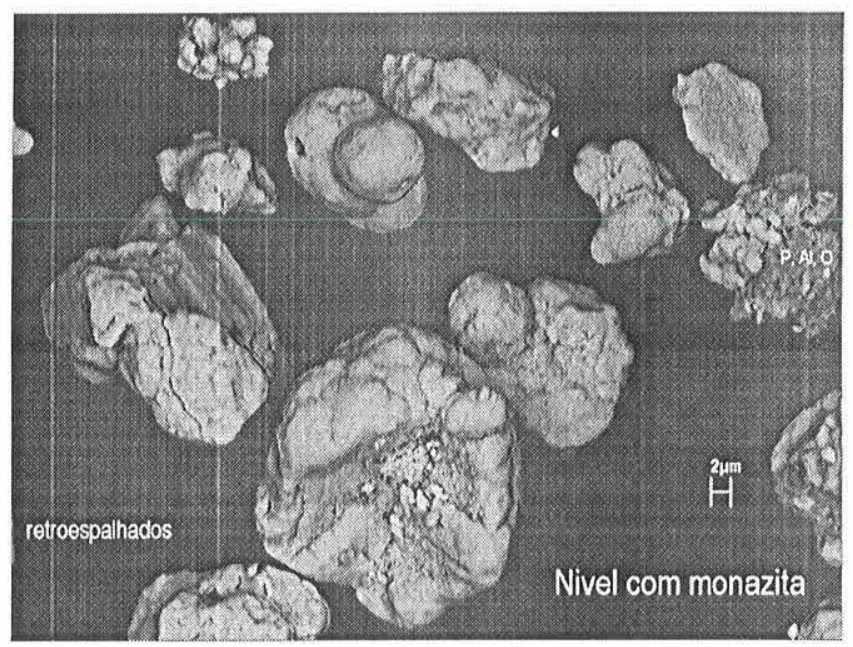

Figura 5 - Agregados concrecionares de monazita (MEV, elétrons retroespalhados). Cortesia de Tassinari (200I). 
Veios milimétricos a centimétricos de monazita cortam indiscriminadamente $\mathrm{C} 1$ e C2., sem orientação preferencial. Os veios são recorrentes, afetando todas as estruturas e litotipos dentro dos pacotes $\mathrm{Cl}$ e C2, à exceção dos pipes (ver abaixo). As características texturais da monazita são semelhantes às descritas para o pacote C2b (Fig. 5)

Diques com espessura variando de milimétrica até $20 \mathrm{~cm}$ afetam principalmente $\mathrm{C} 2$. Nestes o magma parece ter sido bastante fluido, percolando fraturas abertas, e formando bolsões irregulares e uma intrincada rede anastomosada, que contribuiu para a fragmentação hidráulica do conjunto (Fig. 6a). A presença de fraturas em algumas partes do pacote revela que o conjunto $\mathrm{C} 2$ encontrava-se parcialmente consolidado. Em outros locais, entretanto, especialmente próximo à base de C2a, não se observam fraturas e os veios são irregulares e anastomosados, sugerindo percolação passiva (Fig. 6b e $6 \mathrm{c}$ ). Os diques são formados por uma matriz argilosa de cor preta (60$70 \%$ ), sustentando fragmentos milimétricos a centimétricos de rochas do conjunto $\mathrm{C} 2$. Em alguns casos, os diques originamse em camadas de monazita/ilmenita do horizonte C2. São também observados como injeções ao longo da porção central
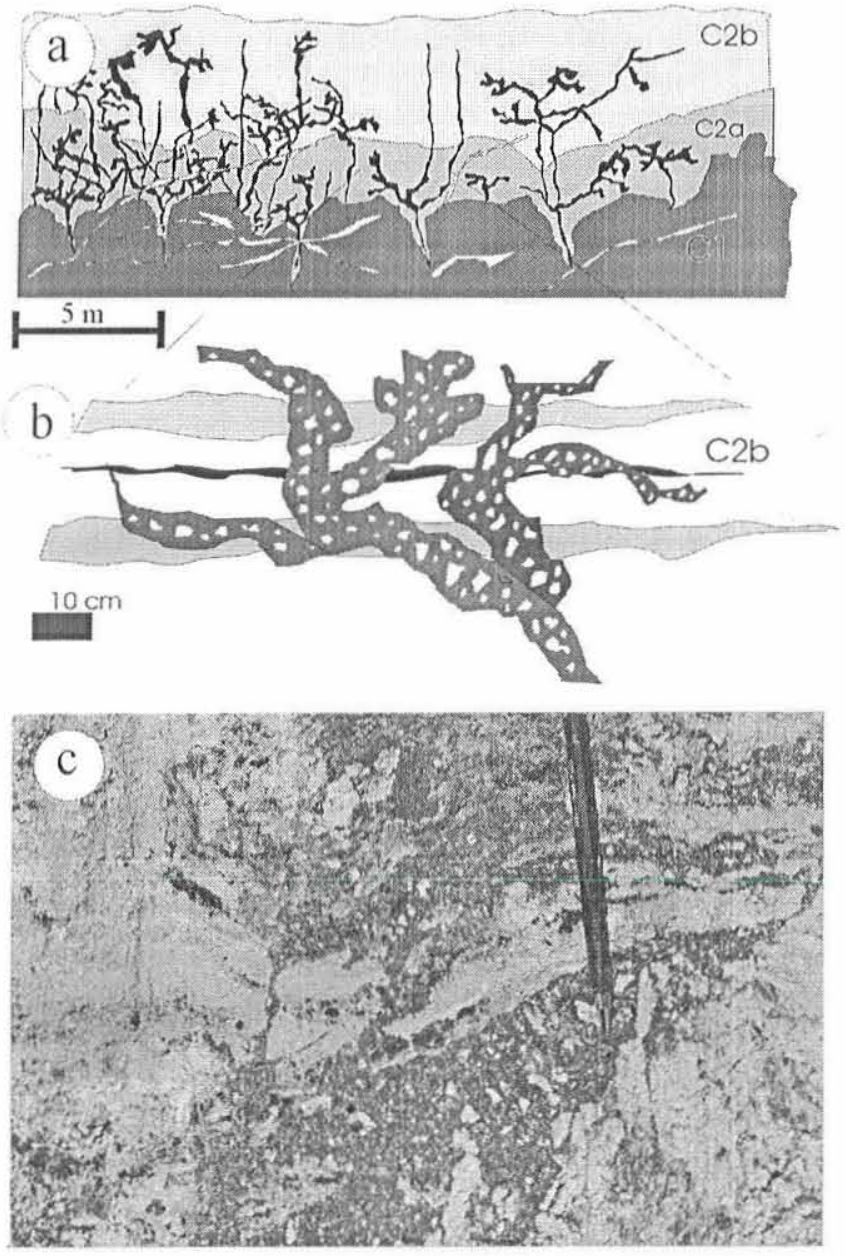

Figura 6-a) e b) Diques irregulares, que percolam e fragmentam as unidades $C 2 a$ e $C 2 b$; c) dique irregular cortando camada de monazita recém formada e incorporando-a como firagmento. dos diques alimentadores de $\mathrm{C} 2$, o que confere um caráter polifásico àqueles. As propriedades descritas indicam que os diques formaram-se imediatamente após o inicio da consolidação das unidades $\mathrm{C} 2 \mathrm{a}$ e $\mathrm{C} 2 \mathrm{~b}$.

Pipes Diversos tipos de pipes cortam o conjunto C2 e seus veios e diques associados. Cerca de 20 pipes foram identificados e catalogados em uma área de $7000 \mathrm{~m}^{2}$, o que determina uma densidade de 0,003 destas estruturas por $\mathrm{m}^{2}$. O termo pipe é utilizado aqui no sentido de Bates e Jackson (1995): "um conduto vertical através da crosta terrestre, abaixo de um vulcão, através do qual materiais magmáticos tenham passado. É usualmente preenchido com brecha vulcânica e fragmentos de rochas mais antigas. Como uma zona de alta permeabilidade, é comumente mineralizado". Para efeitos de descrição de suas variações morfológicas, estruturais e texturais, os pipes foram classificados abaixo em tipos I a V (Fig. 7).

TIPO I - Estes pipes são os mais freqüentes. São preenchidos por brecha semelhante à dos diques descritos em $\mathrm{C} 2$, mas sua morfologia e relação com a encaixante são diferentes. Consistem de condutos cilíndricos com diâmetro variando de 20 a 50 $\mathrm{cm}$ e comprimento de 1 a $2 \mathrm{~m}$, e não parecem provocar fragmentação hidráulica da encaixante. Apesar da forma geralmente cilíndrica, observa-se algumas apófises horizontais curtas nas laterais (Fig. 7 e 8a). Raramente, pipes posteriores podem instalar-se aproveitando parcialmente a mesma abertura.

TIPO II - Formados por condutos semicirculares, preenchidos por brecha, com matriz argilosa e fragmentos na proporção de 1:I. Diferenciam-se dos demais tipos por provocar deformação da encaixante, gerando estruturas semelhantes a dobras de arrasto (Fig. 7). Possuem diâmetro reduzido, com cerca de $10 \mathrm{~cm}$ e, em alguns casos, estão controlados por fraturas. Nas paredes das fraturas, uma camada de argila preta de $1 \mathrm{~cm}$ de espessura sela o contato entre a encaixante e a brecha, e podem-se observar estruturas de esmagamento, ou marcas de pressão, formadas pelo atrito durante arrasto de massa dentro do conduto. $\mathrm{O}$ sentido de movimento registrado pode ser vertical ou oblíquo, para baixo ou para cima. Os pipes do tipo II parecem ser concomitantes ou associados a feições de abatimento do pacote $\mathrm{C} 2$, as quais geram um sistema de fraturas de alto ângulo de mergulho, que tendem a abrir-se para baixo e que controlam, em alguns casos, as injeções de pipes. Alternativamente, as evidências de movimento descendente em alguns pipes deste tipo podem indicar colapso gravitacional do material de preenchimento.

TIPO III - Consiste de condutos semicirculares que podem estar internamente divididos em 3 porções (Fig. 7):

Uma porção basal constituída por um veio de granulação fina e cor cinza muito escura, sem qualquer estrutura interna, com comprimento de 10 a $50 \mathrm{~cm}$ e diâmetro menor que $10 \mathrm{~cm}$, análoga a uma raiz, por onde o pipe poderia ter sido alimentado.

Uma porção intermediária, com forma de bolsão horizontalmente achatado, de seção semicircular, e diâmetro de 40 a 120 $\mathrm{cm}$. Os contatos sugerem feições de dissolução, formando golfos na encaixante (Fig. 9b). Em pelo menos 3 pipes, este conduto está preenchido por material particulado, classificado no tamanho silte a areia grossa, desenvolvendo estratificação plano paralela e cruzada e acamadamento gradacional invertido 
(Fig. $9 \mathrm{ced}$ ).

Uma terceira porção, superior, tem seção semicircular e é preenchida por brecha sustentada por matriz, com fragmentos angulosos, de $1 \mathrm{~mm}$ a $5 \mathrm{~cm}$, cuja proporção aumenta de 10 $15 \%$ na base até $30-40 \%$ no topo. Normalmente esta porção se

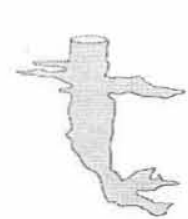

Tipo I

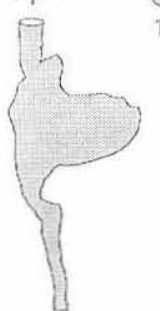

Tipo III

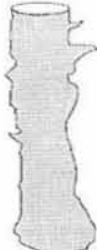

Tipo I

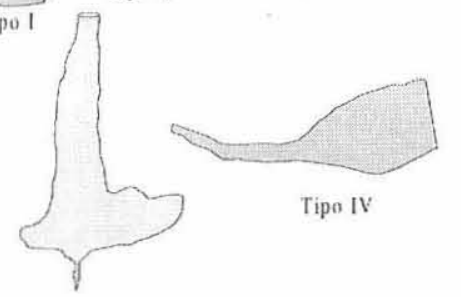

Tipo III

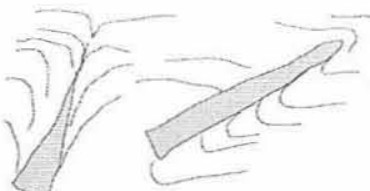

Tipo II Tipo II

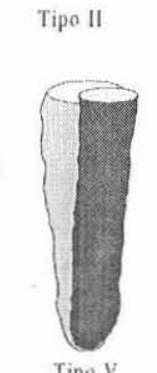

Tipo V

Figura 7 - Tipos de pipes no Complexo de Catalão I.
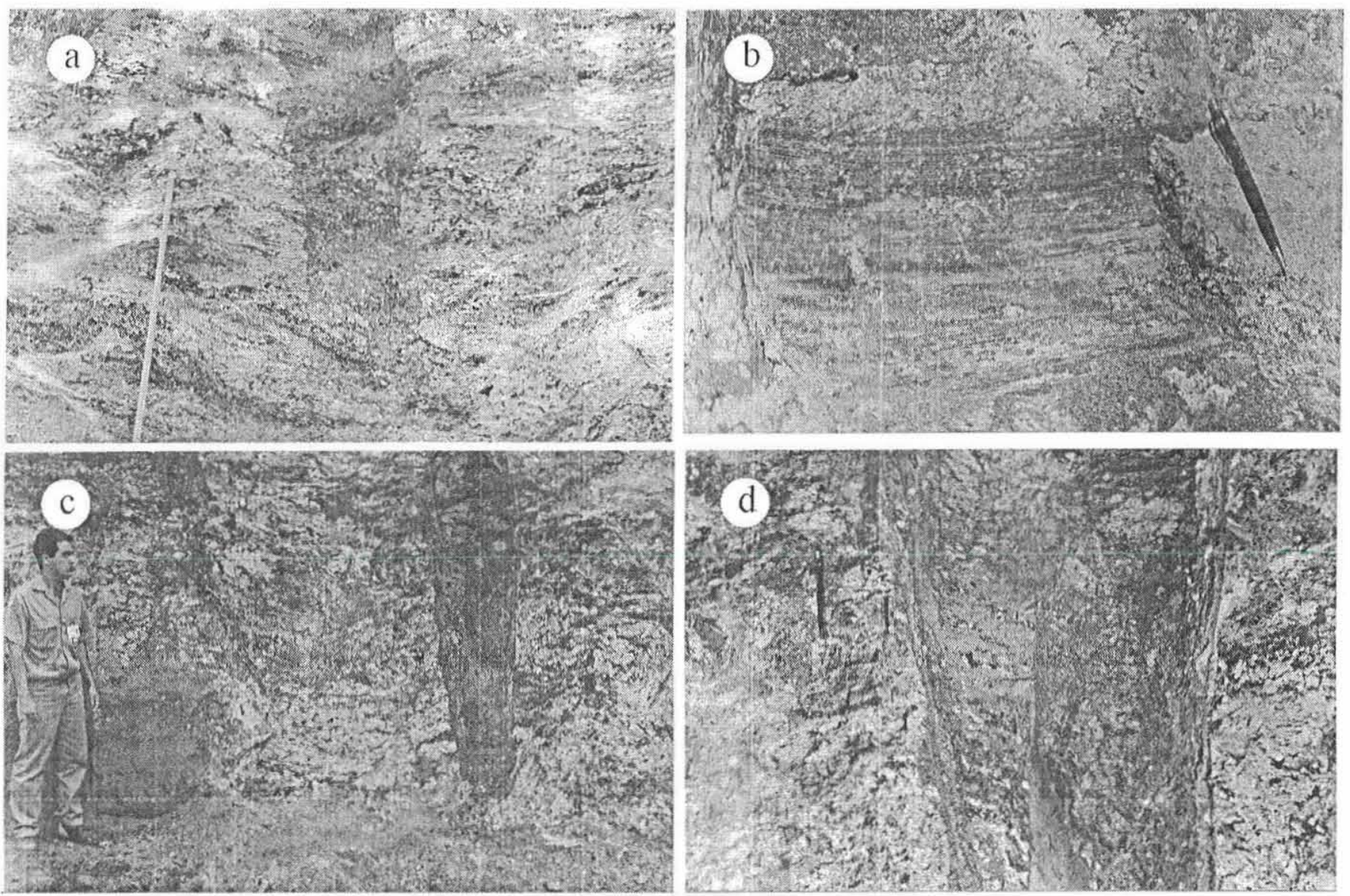

Figura 8-a) Pipe do tipo I, mostrando pequenas apófises horizontais; (b) Estrias deixadas na rocha encaixante pelo fluxo de massa em pipe tipo IV, na posição horizontal; c) Pipe do tipo V, com terminação inferior arredondada d) Pipe recorrente, tipo $V$, cortando pipe mais antigo. Estruturas de fluxo e deformação (sigmóides) no primeiro pipe. 

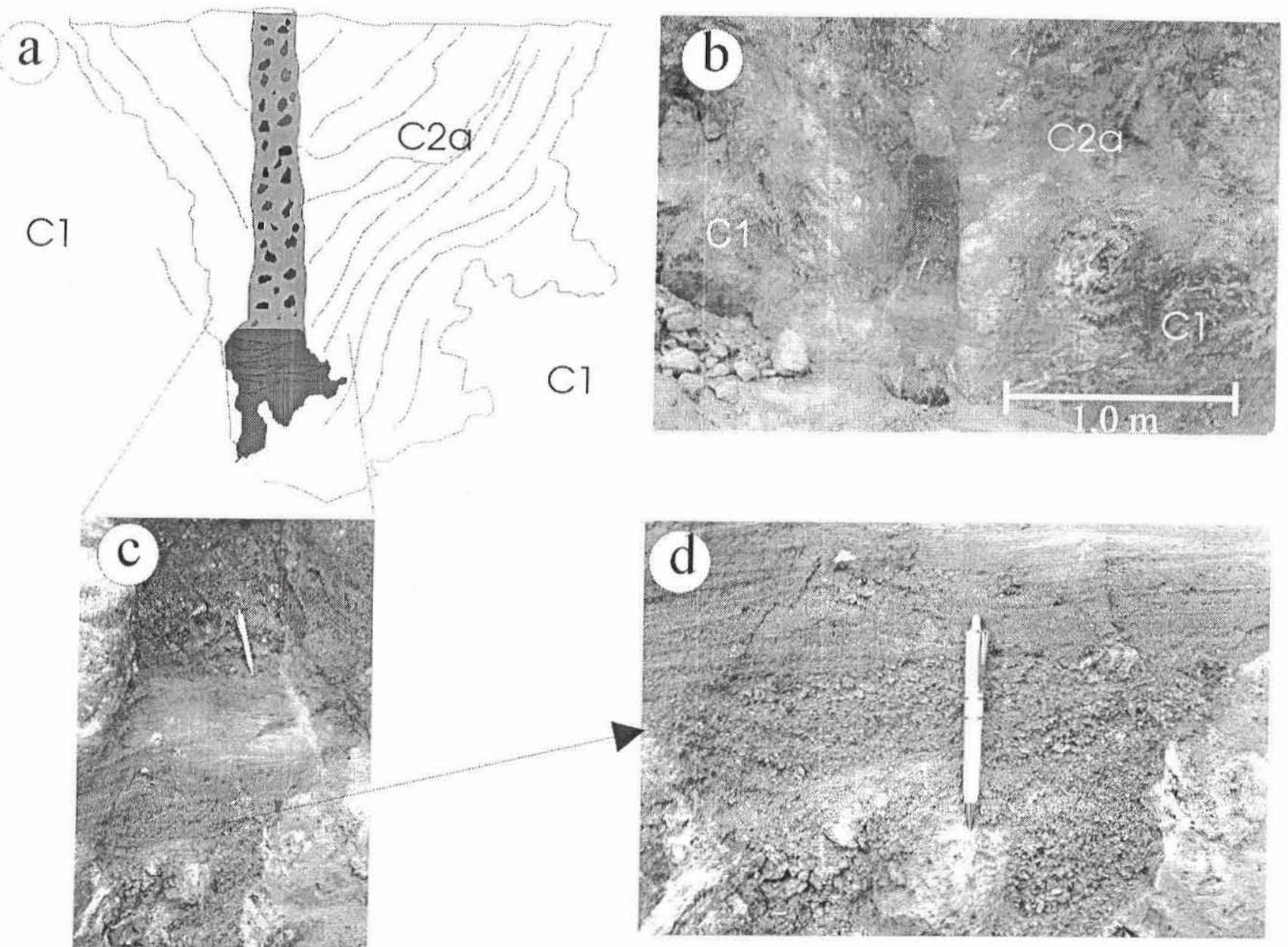

Figura 9-a) e b) Pipe do tipo III, mostrando três seções: inferior; preenchida por material fino sem estrutura, intermediária, mais larga, preenchida por material fino, com estratificação cruzada e plano paralela,e superior; preenchida por brecha; c) e d) detalhe das estratificações plano paralelo e cruzadas na seção intermediária do pipe.

primento atinge os $2 \mathrm{~m}$. Os contatos com a encaixante são retilíneos e bem definidos, sem deformação da encaixante. Observa-se tênues estruturas de fluxo na linha de contato que, como no tipo IV, é marcado por uma camada de argila preta com cerca de $1 \mathrm{~cm}$, cimentando o contato e selando o fluxo de massa dentro do conduto. A terminação inferior deste tipo de pipe é arredondada, sem conexão com veios ou diques, sugerindo movimento de massa no sentido descendente (Fig. 7, 8c). É comum a ocorrência de uma segunda injeção, com as mesmas características da primeira, cortando o primeiro pipe com um ângulo entre $10^{\circ}$ e $40^{\circ}$ graus. Nestes casos, a intrusão do segundo pipe provoca estruturas de deformação tipo sigmóide que indicam o movimento de cima para baixo (Fig. 8d).

Em vários tipos de pipe ocorrem minúsculos glóbulos, com tamanho entre 0.20 e $0.50 \mathrm{~mm}$, compostos por fosfato secundário (gorceixita), possivelmente representando apatita primária pseudomorfizada. Estas estruturas podem ter núcleos de agregados lamelares de ilmenita, núcleos ocos ou, ainda, ser maciças (Fig. 10).

DISCUSSÃO Metassomatismo e conteúdo de voláteis A história geológica dos complexos carbonatíticos da Provín- cia Ígnea do Alto Paranaíba foi marcada por eventos de metassomatismo carbonatítico, que afetaram as encaixantes do complexo em escala relativamente reduzida, mas provocaram profundas transformações nas rochas ultramáficas alcalinas onde está alojada a maioria dos corpos de carbonatito. Diversas linhas independentes de evidência atestam a ocorrências e extensão deste metassomatismo. Sua discussão assume grande relevância para as considerações sobre o conteúdo de voláteis $\mathrm{e}$, consequentemente, para o entendimento da reologia dos magmas envolvidos.

Dentre os vários complexos da Província, Catalão I foi um dos mais afetados por metassomatismo carbonatítico, talvez em intensidade inferior somente ao Complexo do Barreiro (Araxá). Ao contrário de outros autores (Carvalho 1974, Baecker 1983, Danni et al. 1991), Araújo (1996) interpreta os abundantes flogopititos do complexo de Catalão como resultado direto de metassomatismo carbonatítico sobre dunitos, clinopiroxenitos e foscoritos.

Em Catalão I, uma brecha carbonatítica, considerada um dos últimos eventos magmáticos, contém fragmentos de todos os litotipos do complexo (Araújo 1995), mas tanto a matriz quanto os fragmentos são recortados por veios de carbonatito, 

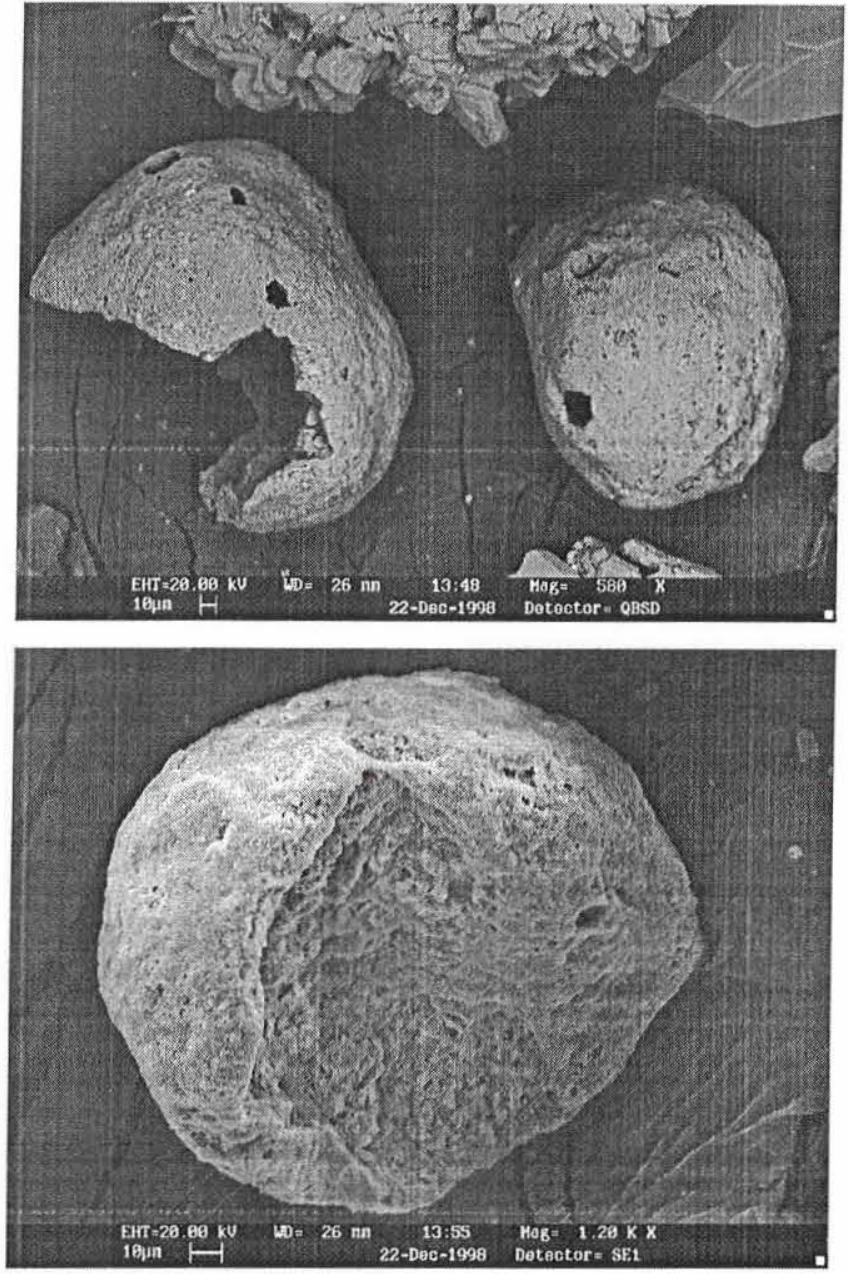

Figura 10 - Imagem MEV de glóbulos de gorceixita encontrados no interior dos pipes.

atestando a recorrência de atividade carbonatítica até os estágios finais de evolução.

Santos \& Clayton (1995) apresentam evidências isotópicas $\delta^{18} \mathrm{O}$ e $\delta^{13} \mathrm{C}$ de alteração hidrotermal intensa sobre os carbonatitos de Catalão I. Segundo aqueles autores, razões $\delta^{13} \mathrm{C}$ variando de -7.1 a $-5.3 \%$ e $\delta^{18} \mathrm{O}$ de 7.3 a $19.3 \%$ podem ser explicadas por trocas isotópicas entre os carbonatitos e fluidos ricos em $\mathrm{H}_{2} \mathrm{O}$ e $\mathrm{CO}_{2}$ a diferentes temperaturas e com distintas razões $\mathrm{H}_{2} \mathrm{O}^{2} \mathrm{CO}_{2}$. No caso de Catalão $\mathrm{I}$, os dados indicam temperaturas abaixo de $300^{\circ} \mathrm{C}$ e fluidos com alta razão $\mathrm{H}_{2} \mathrm{O}$ / $\mathrm{CO}_{2}$.

No Complexo de Tapira, Brod (1999) detectou eventos de desgaseificação de $\mathrm{CO}_{2}$ a partir dos líquidos primitivos do complexo, com base em dados isotópicos de carbono e oxigênio.

Brod et al. (2001) concluíram por uma origem metassomática das coroas de tetra-ferriflogopita circundando núcleos de flogopita magmática em clinopiroxenitos e flogopititos de Catalão I e Tapira. A passagem de uma para outra variedade é brusca e corrobora a origem dos flogopititos por metassomatismo carbonatítico sobre rochas ultramáficas dos complexos.

Estimativas seguras do conteúdo e composição de voláteis em magmas carbonatíticos são raras na literatura, dada a difi- culdade de quantificar a perda de elementos químicos para as encaixantes durante eventos de fenitização. Uma avaliação preliminar (Junqueira-Brod et al., em preparação), com base em composição modal, química mineral e litogeoquímica (Brod 1999), sugere que os magmas mais primitivos (flogopitapicritos) encontrados nos complexos carbonatíticos do Alto Paranaíba possuíam teores médios aproximados de 10-12\% $\mathrm{CO}_{2}, 1$ a $2 \%$ de $\mathrm{H}_{2} \mathrm{O}$ e 0,1 a $0,2 \%$ de $\mathrm{F}$, em peso, e teores de $\mathrm{Cl}$ provavelmente negligíveis. Estimativas de Bühn e Rankin (1999) do conteúdo de voláteis em um magma/fluído carbonatítico tardio, com base em estudos detalhados de inclusões fluidas aprisionadas nas encaixantes do complexo de Kalkfeld, Namíbia, forneceram valores de aproximadamente $20 \% \mathrm{H}_{2} \mathrm{O}$, $20 \% \mathrm{CO}_{2}, 0,5$ a $1,2 \% \mathrm{~F}$ e até 5 a $6 \% \mathrm{Cl}$ em peso. Assim, podese imaginar que os magmas responsáveis pela formação e preenchimento dos pipes e diques da região da Lagoa Seca possuíam conteúdo de voláteis intermediário entre os dois extremos acima, muito provavelmente tendendo mais para o segundo conjunto de valores.

Origem da Lagoa Seca Uma das possibilidades para a origem da Lagoa Seca seria a lixiviação de carbonatos de carbonatitos e foscoritos subjacentes. Este processo, quando não resulta em grandes cavernas que podem levar a dolinas, pode implicar numa diminuição de até cinco vezes o volume original da rocha (Toledo 1999). Em ambos casos forma-se uma depressão que pode variar em tamanho conforme a área exposta de carbonatito. Uma segunda hipótese envolve colapso localizado e de pequena escala, relacionado ao resfriamento e solidificação dos stocks carbonatíticos centrais do domo, o que poderia resultar em uma redução de volume suficiente para o abatimento da parte central do complexo. A distribuição das principais concentrações de fósforo e nióbio, circundando os limites do paleo-lago sugere um provável controle destas mineralizações por estruturas do tipo cone sheets.

Embora não hajam datações disponíveis, os conglomerados basais da Lagoa Seca contêm abundantes fragmentos dos quartzitos encaixantes e de carbonatitos, atestando que no inicio da deposição o complexo já estava parcialmente exposto à superfície por processos erosivos.

Profundidade de intrusão do Complexo de Catalão I Com base em dados de traços de fissão em apatita dos complexos de Tapira e Catalão, e tomando como pressuposto um gradiente geotermal de $27^{\circ} \mathrm{C} / \mathrm{km}$, Amaral et al. (1997) concluíram que a região foi submetida a um resfriamento relativamente lento de $95^{\circ} \mathrm{C}$ a $85^{\circ} \mathrm{C}$ no período entre 90 e $60 \mathrm{Ma}$, seguido de um resfriamento mais rápido, de $85^{\circ} \mathrm{C}$ a $27^{\circ} \mathrm{C}$, entre $60 \mathrm{Ma} \mathrm{e} \mathrm{o}$ presente. Estes dados indicam taxas de erosão estimadas de 12 $\mathrm{m} / \mathrm{Ma}$ entre 90 e $60 \mathrm{Ma}$, e $36 \mathrm{~m} / \mathrm{Ma}$ nos últimos $60 \mathrm{Ma}$.

Embora deva se ressaltar que tais estimativas dependem da apatita atingir uma temperatura baixa o suficiente para permitir a preservação dos traços de fissão, um cálculo simples, baseado nas taxas de erosão propostas por Amaral et al. (1997), sugere a intrusão dos complexos de Tapira e Catalão a profundidades máximas em torno de apenas $2,5 \mathrm{~km}$. Se for considerado apenas o período de alta taxa de erosão, a partir de $60 \mathrm{Ma}$, esta estimativa cai para $2,16 \mathrm{~km}$. Finalmente, há que se considerar que pelo menos $150 \mathrm{~m}$ de sedimentos foram depositados na bacia da Lagoa Seca, após a exposição das rochas do complexo, por erosão. Embora não se conheça o tempo transcorrido entre o afloramento das rochas plutônicas e o início da 
deposição dos sedimentos, e tampouco o tempo decorrido desde o final da sedimentação até a implantação do regime erosivo atual, quanto maiores forem estes intervalos, tanto mais reduzida será a estimativa de profundidade. Portanto, é possível que a profundidade real de intrusão do complexo seja consideravelmente menor do que $2 \mathrm{~km}$. Trabalhos de datação palinológica dos sedimentos da Lagoa Seca encontram-se em andamento, com o objetivo de obter uma definição mais precisa destes valores.

As evidências de campo, petrográficas, isotópicas e de química mineral no complexo de Catalão I indicam que os magmas carbonatíticos foram submetidos a intensa desgaseificação, que culminou na transformação generalizada das encaixantes ultramáficas em flogopititos. Mesmo os magmas ultramáficos mais primitivos nos complexos carbonatíticos, como os flogopita-picritos do complexo de Tapira, mostram evidências de desgaseificação (Brod 1999). Isto é consistente com uma intrusão rasa o suficiente para permitir a perda de voláteis magmáticos exsolvidos, pois a pressão do magma deve exceder a pressão litostática.

Origem dos pipes Em estruturas sub-vulcânicas erodidas como a descrita neste trabalho, é possível reconhecer a presença de condutos que alimentaram a ascenção ou erupção do magma, sempre que a pressão magmática tenha sido suficiente para alcançar a superfície. Estes condutos podem ocorrer em uma gama de geometrias, dentre as quais as mais comuns são diques planares e condutos semicirculares (pipe-like).

O preenchimento de pipes quase sempre se dá pelo resfriamento de magma não-fragmentado, uma vez que normalmente a fragmentação do líquido por exsolução de gases ocorre em níveis próximos à superfície. A exsolução de água é a causa mais comum de fragmentação do magma, mas quando a porcentagem relativa de $\mathrm{CO}_{2}$ exsolvido é alta, há um incremento na saturação do magma e uma exsolução mais precoce (Papale 1998), possibilitando a fragmentação em níveis mais profundos. Não há modelos experimentais conhecidos que ajustem curvas de pressão inicial de gás dissolvido em líquidos carbonatíticos como o descrito neste trabalho. Não obstante, o inevitável decréscimo da pressão no interior do conduto, como conseqüência da alta participação de $\mathrm{CO}_{2}(>15 \% \mathrm{em}$ peso), implica em rebaixamento do nível de fragmentação (Papale 1998)

Os pipes analisados podem ser considerados como condutos vulcânicos que partiram da câmara até a superfície, com um extremo hidráulico "livre", sem um bloqueio que suporte a pressão. Propagaram-se não apenas verticalmente, buscando superar a pressão litostática, mas também no sentido horizontal, desgaseificando progressivamente a câmara. A presença de condutos horizontais é um argumento válido para interpretar uma câmara magmática como rasa, já que a despressurização se produziu na direção dos componentes de esforço horizontais $(\sigma 2-\sigma 3)$ do estado de tensão da crosta.

O material de preenchimento dos pipes descritos, em todos os casos é uma massa de material fragmentado, com matriz fina abundante, cujas características texturais e estruturais podem ser utilizadas para interpretar o processo de formação. Não houve uma única dinâmica de fluxo dentro dos condutos, já que em alguns casos há evidências de fluxos densos, com razão sólido/gás $>1$, tais como cisalhamento nas paredes do conduto (Fig. 8d-pipes tipo V), enquanto outros contêm estruturas como estratificação cruzada e laminação paralela, eviden- ciando diluição do componente sólido (fig. 9 - pipes tipo III). Precisamente nestes últimos há um incremento de material fino na porção basal do pipe, o que pode indicar: a) decréscimo paulatino na pressão de escape de gás+sólido, à medida que evolui a desgaseificação da câmara, perdendo poder de transporte; ou b) aumento na eficiência da fragmentação do magma.

As estruturas descritas nos pipes indicam exsolução de gases e nucleação de bolhas previamente à formação destes. Para a composição de magma considerado, com a soma dos conteúdos em peso de $\mathrm{CO}_{2}, \mathrm{H}_{2} \mathrm{O}$ e F de no mínimo $11 \%$, pode-se estimar uma profundidade mínima de $3.4 \mathrm{~km}$ para a formação de bolhas de $\mathrm{CO}_{2}$ e de $130 \mathrm{~m}$ para a formação de bolhas de $\mathrm{H}_{2} \mathrm{O}$ (Wilson e Head 1981). Considerando o teto da câmara a menos de $1 \mathrm{~km}$ de profundidade e a uma pressão de $\sim 20 \mathrm{MPa}$, com um conteúdo de voláteis de $11 \%$ sendo exsolvido e produzindo uma baixa integral na densidade do magma, é viável obter níveis de fragmentação e formação de partículas tamanho lapilli, muito próximo ao próprio nível de nucleação.

A nucleação de bolhas em um conduto começa a diâmetros de $20 \mu \mathrm{m}$ (Sparks 1978) e continua, dependendo do tipo e concentração de gases contidos no magma. Se a primeira espuma gerada no teto da câmara teve bolhas com diâmetro de $20 \mu \mathrm{m}$ e uma viscosidade de 10MPa.s, obviamente estava mais do que instável e na iminência de fragmentação, uma vez que espumas de líquidos com viscosidade desta ordem, como os carbonatitos, são instáveis com bolhas de até aproximadamente 1 mm de diâmetro (Proussevitch et al. 1993).

Os modelos disponíveis para cálculos de exsolução de voláteis e formação de condutos em magmas com baixo teor de sílica são aplicáveis a composições basálticas. Assim, a coexistência de níveis de nucleação e fragmentação muito próximos entre si e, ademais, localizados muito próximo ou mesmo dentro do reservatório magmático, pode ser uma característica especial de magmas carbonatíticos acumulados próximo à superfície. Neste caso, um tipo especial de efervescência secundária (second boiling) seria o principal gatilho para a formação dos pipes, onde o excesso de $\mathrm{CO}_{2}$ seria gerado pela desestabilização do $\mathrm{CO}_{3}{ }^{2-}$ dissolvido no líquido carbonatítico.

CONCLUSÕES Os pipes de brecha descritos no Complexo de Catalão I possuem uma gama de geometrias e seu material de preenchimento compreende desde brechas com amplas variações na razão fragmentos/matriz até material fino, com ou sem estratificação. A dinâmica de fluxo dentro destes condutos foi variável, desde fluxos de alta densidade, com razão sólido/ gás >1 até fluxos diluídos, com alto grau de fragmentação magmática.

De especial interesse são as estruturas indicativas de transporte particulado, como acamadamento gradacional e estratificações cruzadas. Estas estruturas são normalmente geradas durante transporte e deposição de partículas individualizadas em um sistema diluído, em regime de fluxo turbulento, como na sedimentação em ambiente aquoso ou eólico, ou nos fluxos de baixa densidade (surges) em ambientes vulcânicos. Os pipes contendo tais estruturas (Tipo III) poderiam ser explicados por um sistema de canais dentro do conjunto de rochas em processo final de solidificação. A figura 11 mostra um modelo possível, baseado em feições de campo e interpretações dos autores.

A presença de brechas em todos os tipos de pipes, sugere explosões internas nestes condutos, as quais, ao mesmo tempo que provocaram a falência ou quebra rúptil do material sobrejacente, abriram espaço suficiente para a movimentação dos fluxos diluídos na parte inferior dos pipes. 
Para o funcionamento dos processos sugeridos de formação dos pipes é necessário que se gerem e se mantenham abertos os espaços necessários ao transporte e deposição de material particulado em fluxo diluído, o que requer que a pressão do magma suplante a pressão litostática. Isto é consistente com as estimativas de profundidade de intrusão e teor de voláteis no magma, as quais sugerem que a pressão magmática na câma-

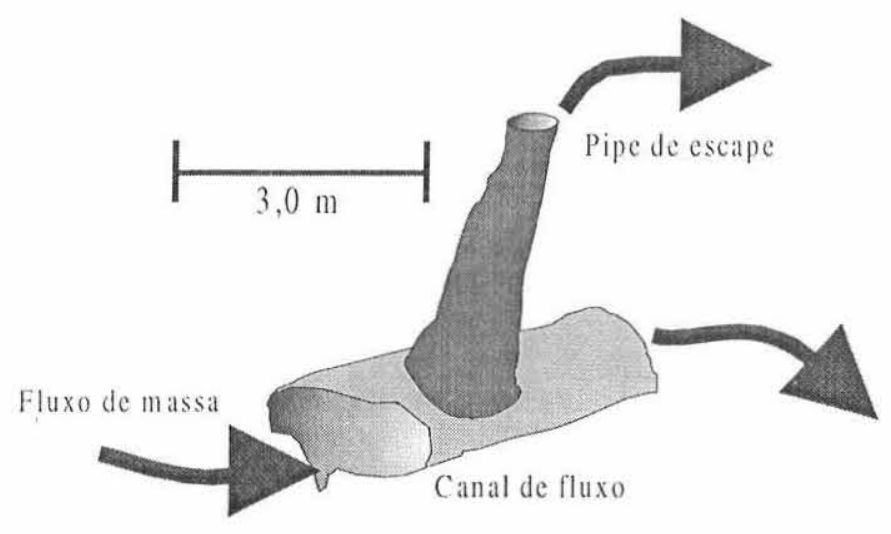

Figura II - Modelo de formação dos pipes da região da Lagoa Seca ra poderia ser uma ou duas ordens de magnitude maior que a pressão litostática, especialmente em região de crosta relativamente estável, submetida a processos distensivos, como era o caso do Alto Paranaíba durante o Cretáceo.

Do exposto, espera-se que um líquido com as características reológicas consideradas, acumulado muito próximo à superfície, culmine seu resfriamento de maneira explosiva, com a formação de níveis de fragmentação muito próximos ou no próprio teto do reservatório.

Os argumentos apresentados demonstram que a atividade explosiva, a fragmentação do magma e o transporte e deposição de material particulado em fluxo diluído e turbulento foram viáveis em ambiente intra-câmara magmática, no complexo carbonatítico de Catalão I. As descrições e interpretações contidas neste artigo seriam um caso extremo de formação de surges ao nível do conduto ou do teto da câmara magmática, portanto desenvolvido a pressões diferentes da atmosférica.

Agradecimentos Este trabalho é parte de uma tese de doutoramento do primeiro autor e contou com o apoio da empresa Ultrafertil SA. Os autores agradecem ao geólogo Neumamn Reiner do CETEM e da geóloga Emanuela Tassinari do LCT- USP pela cessão das imagens MEV aqui apresentadas. I.A. Petrinovic agradece o apoio financeiro aos projetos PICT9803817 e CIUNSa 815 e à Secretaria de Minería, Industria y Recursos Energéticos de la Província de Salta. Aos revisores da RBG pelas sugestões ao manuscrito.

\section{Referências}

Amaral G., Born H., Hadler J.C., Iunes P.J., Kawashita K., Machado D.L., Oliveira E.P., Paulo S.R., Tello C.A. 1997. Fission track analysis of apatites from São Francisco craton and Mesozoic alkaline-carbonatite complexes from central and southeastern Brazil. J. South Amer: Earth Sci., 10: 28.5-294.

Araújo D.P. 1996. Metassomatismo no complexo carbonatítico Catalão-I: implicações para a composição do magma carbonatítico e para o metassomatismo carbonatítico no manto superior. Dissertação de mestrado, Universidade de Brasília.

Baecker M.L. 1983. A mineralizașion de nióbio do solo residual laterítico e a petrografia das rochas ultramáfica alcalinas do domo de Catalão I. Goicis. Dissertação de Mestrado, Universidade de Brasília, Brasília.

Brod J.A. 1999. Petrology and geochemistry of the Tapira alkaline complex, Minas Gerais State, Brazil. PhD thesis, University of Durham, UK.

Brod J.A., Gibson S.A., Thompson R.N., Junqueira-Brod T.C., Seer H.J., Moraes L.C., Boaventura G.R. 2000. Kamafugite afinity of the Tapira alkalinecarbonatite complex (Minas Gerais, Brazil), Rev. Bras. Geoc. 30:404-408.

Brod J.A., Gaspar J.C., Araujo D.P. Gibson S.A., Thompson R.N., JunqueiraBrod, T.C. 2001. Phlogopite and tetra-ferriphlogopite from Brazilian carbonatite complexes: petrogenetic constraints and implications for mineral-chemistry systematics. J. Southeast Asian Earth Sci., 19:265-296.

Bates R.L. \& Jackson J.A. 1995. Glossary of Geology-Third Edition 1995. American Geological Institute. Alexandria, Virginia.

Bühn B \& Rankin A.H., 1999. Composition of natural, volatile-rich Na-Ca-REESr carbonatitic fluids trapped in fluid inclusions. Geoch. Cosmochem. Acta, 63:3781-3797.

Carvalho W.T. 1974. Aspectos geológicos e petrográficos do complexo ultramáfico-alcalino de Catalīo I, GO. In: SBG, Congr. Bras. Geol., 28. Porto Alegre, Anais, 5:107-123.

Danni J.C.M., Baecker M.L., Ribeiro C.C. 1991. The geology of the Catalão I carbonatite complex. In: O.H. Leonardos, H.O.A. Meyer, J.C. Gaspar (Eds.). Field Guide Book of the 5 th International Kimberlite Conference.

\section{Araxá, CPRM, 25-30}

Gaspar J.C. \& Araújo D.P. 1995. Reaction products of carbonatite with ultramafic rocks in the Catalão I complex, Brazil: possible implications for mantle metasomatism. In: International Kimberlite Conference, 6, Novosibirsk, Evtended Abstracts, 181-183.

Gaspar J.C., Silva A.J.G.C.. Araújo D.P. 1994. Composition of priderite in phlogopitites from the Catalão I carbonatite complex, Brazil. Min. Mag.. 58:409-415.

Gibson S.A., Thompson R.N., Leonardos O.H., Dickin A.P., Mitchell J.G., 1995. The Late Cretaceous impact of the Trindade mantle plume- evidence from large-volume, mafic, potassic magmatism in SE Brazil. J. Petrol., 36:189229.

Gibson S.A., Thompson R.N., Weska R.K., Dickin A.P., Leonardos O.H. 1997. Late Cretaccous rift-related upwelling and melting of the Trindade starting mantle plume head beneath western Brazil. Contrib. Mineral. Petrol., 126:303-314.

Gierth E. \& Baecker M.L. 1985. A mineralização de nióbio e as rochas alcalinas associadas no complexo Catalão I, Goiás. In: C. Schobbenhaus (Ed.). Principais depósitos minerais do Brasil, vol. 2. Brasília, MME/DNPM, 456462.

Gomes C.B., Ruberti E., Morbedelli L. 1990. Carbonatitic complexes from Brazil: A review. J. South Amer: Earth Sci., 3:51-63.

Herz N. 1977. Timing and spreading in the South Atlantic: information from Brazilian alkaline rocks. Geol. Soc. Am. Bull., 88:101-112.

Neumann R. 1999. Caracterizaşão Tecnológica dos potenciais minérios de Terras Raras de Catalão I. Tese de Doutorado, Universidade de São Paulo-USP.

Papale P. 1998. Volcanic conduits dynamics. In: A. Freundt \& M Rossi (eds): From magna to tephra. Elsevier, 55-89.

Pereira V.P. 1995. Alteraşão no Maciço Alcalino-Carbonatítico de Catalão I. Tese de Doutorado. UFRGS, Instituto de Geociências 
Proussevitch A.A., Sahagian D.L., Anderson A.T. 1993. Dynamics of effusive buble growth in magmas: isothermal case. J.Geophys.Res. 98:22,28322,307

Ribeiro C.C. \& Gaspar J. C. 2000. Hydrothermal features in the Catalão I Carbonatite Complex, Goiás. An. Acad. Bras. Ciênc., 72(4).

Santos R.V., Clayton R.N. 1995. Variations of oxygen and carbon isotopes in carbonatites - a study of Brazilian alkaline complexes. Geoch. Cosmochim. Acta 59:1339-1352

Seer H.J. \& Moraes L.C. 1988. Estudo petrográfico das rochas ígneas alcalinas da região de Lagoa Formosa, MG. Rev. Bras. Geoc., 18:134-140.

Seer H.J., Moraes L.C., Fogaça A.C.C. 1989. Roteiro geológico para a regiāo de Lagoa Formosa-Chumbo-Carmo do Paranaíba, MG. SBG, Belo Horizonte, $58 \mathrm{p}$.

Silva A.N., Marchetto M., Souza O.M. 1979. Geologia do complexo carbonatítico de Araxá, Minas Gerais. Min. Metal., 43:14-18.

Sparks R.S.J. 1978. The dynamics of bubble formation and growth in magmas: a review and análisis. J.Volcanol.Geotherm.Res., 3:1-37

Tassinari M.M.M.L. 2001. Caracterizaşão tecnológica do depósito de Terras Raras de Catalão I. GO. Áreas: Córrego do Garimpo e Lagoa Seca. Tese de Doutorado. Escola Politécnica. Departamento de Engenharia de Minas. USP.
Thompson R.N., Gibson S.A., Mitchell J.G., Dickin P., Leonardos O.H., Brod J.A., Greenwood J.C. 1998. Migrating Cretaceous-Eocene magmatism in the Serra do Mar alkaline province, SE Brazil: melts from the deflected Trindade mantle plume? J. Petrol. 39:1493-1526.

Toledo M.C.M. 1999. Mineralogia dos principais fosfatos do maciço alcalinocarbonatítico de Catalão I (GO) e sua evolușão no perfil laterítico. Tese de Livre Docência, Instituto de Geociências, USP.

Toyoda K., Horiuchi H., Tokonami M. 1994. Dupal anomaly of Brazilian carbonatite: geochemical correlation with hotspots in the South Allantic and implications for the mantle source. Earth Planet. Sci. Lett., 126:315-331.

VanDecar J.C., James D.E., Assumpção M. 1995. Seismic evidence for a fossil mantle plume beneath South America and implications for plate driving forces. Nature 378:25-31.

Wilson L. \& Head J.W. 1981. Ascent and eruption of basaltic magma on the earth and moon. J. Geophys. Res., 86:2971-3001

Manuscrito A - 1233

Recebido em 11 de junho de 2001 Revisão dos autores em 20 de novembro de 2001 Revisão aceita em 30 de novembro de 200 